\title{
Influence of temperature on the chemo-enzymatic epoxidation of citronellol
}

\author{
Jaqueline Maria Ramos da Silva and Maria da Graça Nascimento \\ Departamento de Química, Universidade Federal de Santa Catarina - 88040-900 Florianópolis - SC. \\ Tel./Fax: +55-48-37219968; *e-mail: jaquelinemrs@yahoo.com.br
}

Keywords: citronellol, chemo-enzymatic epoxidation, temperature

\section{INTRODUCTION}

Citronellol, or dihydrogeraniol, is a natural acyclic monoterpenoid. The oxidation of terpenes has important industrial applications considering that terpene epoxides are used as starting materials for the synthesis of commercially important fragrances and flavoring materials ${ }^{1}$. The use of enzymes in the chemo-enzymatic epoxidation of double bonds has been widely used recently. Lipase obtained from Candida antarctica B (CAL-B) has outstanding efficiency in the catalysis of the perhydrolysis of octanoic acid. The simplicity of the process, the efficiency at normal temperature and pressure, and reuse of the catalyst have been shown to be great advantages. $^{2,3}$

\section{RESULTS AND DISCUSSION}

In this study, the influence of temperature on the chemo-enzymatic epoxidation of the terpene alcohol citronellol (1) was evaluated using $20 \mathrm{mg}$ of lipase from Candida antarctica B, CAL-B (Novozym 435 $10,000 \mathrm{U} / \mathrm{g}), 470 \mathrm{mg}$ (5 mmol) of urea hydrogen peroxide (UHP) as the oxidant agent and $0.32 \mathrm{~mL}(2$ $\mathrm{mmol}$ ) of octanoic acid as the acyl donor in acetonitrile (Scheme 1).

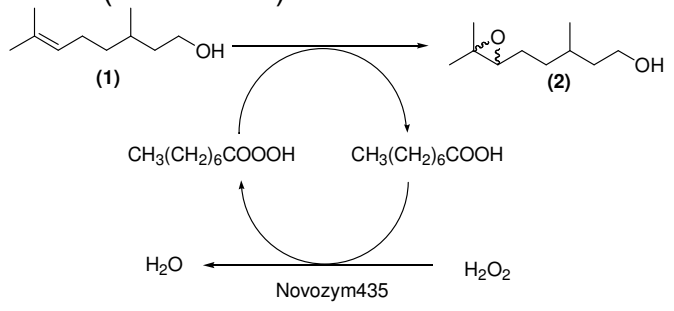

$\overbrace{(2)}^{\sim} \sim_{\mathrm{OH}} \underset{\text { Novozym435 }}{\stackrel{\mathrm{CH}_{3}\left(\mathrm{CH}_{2}\right)_{6} \mathrm{COOH}}{\longrightarrow}}$

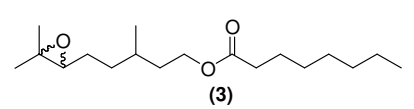

Scheme 1- Chemo-enzymatic epoxidation of citronellol.

The reactions were performed under orbital agitation on a Shaker (150 rpm) at controlled temperatures of $15,20,25,30,35,40$ and $45^{\circ} \mathrm{C}$. After $24 \mathrm{~h}$, aliquots were removed from the reaction media and the formation of epoxy-citronellol (2) or epoxy ester epoxide (3) was quantified by ${ }^{1} \mathrm{H}$ NMR (400 MHz).
The formation of (2) was confirmed by the presence of a peak at $2.70 \mathrm{ppm}$ related to oxirane ring hydrogen and the absence of a triplet at 5.06 ppm, which is characteristic of the hydrogen of the double bond. Another relevant finding was that in the ${ }^{1} \mathrm{H}$ NMR spectra, a triplet centered at 4.13 ppm was observed which was assigned to the methylene hydrogens of ester epoxide (3). The conversion degrees in (2) and (3) as a function of temperature are presented in Table 1.

Table 1- Influence of temperature on the degree of conversion of (2) and (3).

\begin{tabular}{c|c|c}
\hline $\begin{array}{c}\text { Temperature } \\
\left({ }^{\circ} \mathbf{C}\right)\end{array}$ & $\begin{array}{c}\text { Epoxide (2) } \\
\text { (\%) }\end{array}$ & $\begin{array}{c}\text { Ester epoxide (3) } \\
\text { (\%) }\end{array}$ \\
\hline 15 & 71 & 29 \\
20 & 87 & 13 \\
25 & 83 & 17 \\
30 & 79 & 21 \\
35 & 59 & 41 \\
40 & 65 & 35 \\
45 & 75 & 25 \\
\hline
\end{tabular}

Reaction conditions: citronellol (2 mmol), UHP (5 mmol), octanoic acid $(2 \mathrm{mmol})$, CALB $(20 \mathrm{mg})$, acetonitrile $(10 \mathrm{~mL})$.

In this temperature range, both products (2) and (3) were formed. However, at $20^{\circ} \mathrm{C}$ and $25^{\circ} \mathrm{C}$ the formation of (2) was favored, forming the epoxide (2) in conversion degrees of $87 \%$ and $83 \%$, respectively.

\section{CONCLUSION}

We investigated the chemo-enzymatic epoxidation of citronellol mediated by CAL-B, and two products were detected by ${ }^{1} \mathrm{H} N M R$, these being the epoxide (2) and the epoxide ester (3). The epoxide (2) was obtained in conversion degrees of $61-87 \%$, regardless the reaction temperature.

\section{ACKNOWLEDGEMENTS}

UFSC, CNPq, CAPES, INCT-Catálise, Novozymes.

\section{REFERENCES}

1-Moreira M. A., Nascimento M. G.; Catal. Commun. 2007, 8, 2043-2074. 2-Tzialla A. A., Pavlidis I. V., Felicissimo M. P., Rudolf P., Gournis D., Stamatis H. Biores. Technol.; 2010, 101, 1587-1594.

3-Silva W. S. D., Lapis A.A.M., Suarez, P. A. Z., Neto, B. A. D. ; J.Mol. Catal. B: Enzym., 2011, 68, 98-103. 